\title{
A case for Service-Oriented Architecture in Support of Arctic C4ISR
}

\author{
Dan Brookes \\ Defence R\&D Canada, Ottawa \\ Ottawa, ON Canada \\ Dan.Brookes@drdc-rddc.gc.ca \\ Christopher Helleur \\ Defence R\&D Canada, Ottawa \\ Ottawa, ON Canada \\ chris.helleur@drdc-rddc.gc.ca \\ Michael Gingell \\ General Dynamics Canada \\ Dartmouth, NS Canada \\ michael.gingell@gdcanada.com
}

\begin{abstract}
In this paper, we present the challenges that will be faced in maintaining Arctic Domain Awareness and the Arctic C4ISR issues that will result from these challenges. We have discussed the characteristics of the legacy client-server system and how it limits the exploitation of all available data. The characteristics of a Service-oriented Architecture that could address some of these issues are presented. Based upon our Serviceoriented Architecture research and our experience in developing a test-bed to support sensor integration we have proposed an architecture that can contribute to addressing these Arctic C4ISR issues. Our experience and results to date strongly suggest that the benefits derived by adapting a Service-oriented Architecture warrant the effort needed to fully develop this capability.
\end{abstract}

Keywords: Arctic Domain Awareness, C4ISR, Arctic surveillance, Service Oriented Architecture, SOA

\section{Introduction}

Arctic Domain Awareness (ADA) is defined, for the purpose of this paper (based on [1]\&[2]), as "the effective understanding of anything associated with the Arctic environment that could impact security, safety, economy or environment". ADA requires both a process and an infrastructure. The process consists of

1. collecting data, information, and intelligence,

2. collating, correlating, analyzing, and interpreting the collected material,

3. disseminating actionable intel to appropriate federal, state, local, private, and international stakeholders.

\author{
Bill Campbell \\ Defence R\&D Canada, Atlantic \\ Dartmouth, NS Canada \\ Bill.Campbell@drdc-rddc.gc.ca \\ Rahim Jassemi-Zargami \\ Defence R\&D Canada, Ottawa \\ Ottawa, ON Canada \\ Rahim.Jassemi@drdc-rddc.gc.ca
}

4. providing effective assessment, actionable intelligence, and relevant knowledge, and

The infrastructure is provided by the Command, Control, Computing, Communication, Intelligence, Surveillance and Reconnaissance (C4ISR) system. Effective ADA results from leveraging all available capabilities and requires integration of information from national, international and non-government sources. The information source diversity and difficulty conducting surveillance and reconnaissance in the Arctic present unique challenges for Arctic C4ISR (A-C4ISR).

Legacy systems are based on client-server architectures. The objective of this paper is to make the case for the use of a Service Oriented Architecture (SOA) to support Arctic C4ISR.

This paper consists of four elements: 1) describing the challenges unique to A-C4ISR, 2) identifying the characteristics of a SOA that could benefit A-C4ISR, 3) proposing an A-C4ISR architecture based on an investigation of an existing capability, and 4) proposing a way-ahead for SOA architecture development.

\section{The Arctic C4ISR Challenge}

Surveillance, reconnaissance and information collection for the Arctic domain presents a number of unique challenges. Figure 1 presents a model of C4ISR with the Arctic issues indicated. 


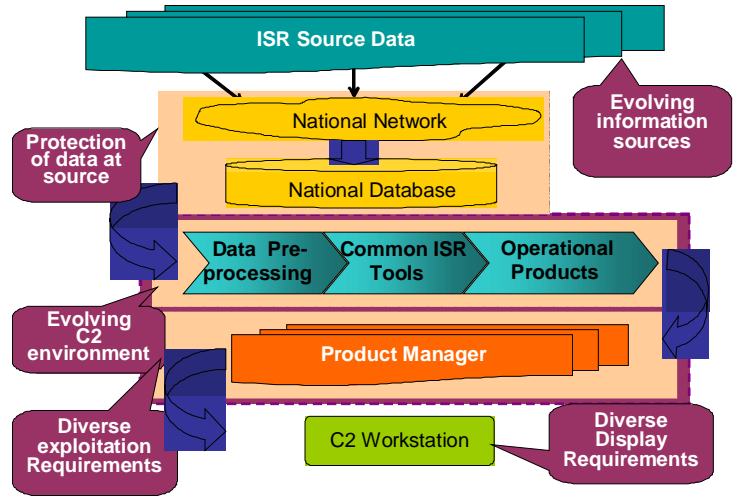

Figure 1: Arctic issues for information flow and tools.

\subsection{Diverse information sources}

Effective ADA results by leveraging all available capabilities including military, non-military governmental, international partners and agencies, non-government agencies and industry. The willingness of these sources to share information and their ability to do so will vary. Therefore successful A-C4ISR must be capable of supporting this multi-D control of access to information.

\subsection{Continual change to the ISR mix}

The capability supports the nature of activity that the Arctic has experienced in the past. If the polar ice cap continues to recede, and economic interests in the Arctic increase, the level of maritime traffic and other activity in the Arctic will gradually increase. This will require a greater level of domain awareness as this activity impacts the security, the safety, the economy and the environment of those in the Arctic and around the world.

This continual increasing demand for ADA will put increasing stress on the Arctic C4ISR architecture; hence it must be capable of including new information and surveillance sources as they become available. Figure 2 tries to convey the complex nature of the ISR sourcing.

The source platforms can be grouped according to increasing proximity to the Earth i.e. satellites, airborne platforms, and surface or sub-surface platforms (including the Earth itself). These groupings can then be successively broken down according to ownership (civilian vs. military, commercial vs. governmental, etc.) and ultimately according to the final class of platform (satellite type, vessel type, vehicle type, man-portable or stationary).

Difficulties arise in trying to use data or intelligence from such a diverse set because, in many cases, the ISR sources were originally designed with different requirements in mind, thus affecting the data format, precision, latency, etc.; this is generally referred to as "stove-piping". In addition, some platform sources are multi-functional in nature so, although the sensor(s) on a particular platform may meet the requirements of two different end-users, the different operating modes may not be optimal for all users.
A case in point is Synthetic Aperture Radar (SAR) imagery from Radarsat 1 (or 2 in future). Several Canadian governmental departments such as Environment Canada/Canadian Ice Services, the ISTOP program and DND may have competing/conflicting requirements for imagery from Radarsat 1/2; where one might need a high resolution, narrow swath image, the other might require a lower resolution, wider swath. The requirements for the different departments, from the same sensor, include such diverse activities as ice/iceberg detection, wind and ocean currents, pollution (oil spill) detection and ship detection. This competition for time and resources could be ameliorated somewhat by a constellation of several satellites that may become available in the future; however, at present the revisit rate is of the order of a day. Also although the imagery may not be optimal for a particular application, it may be sufficient, and having all images acquired by all Government of Canada departments available through a common database, or information link/architecture would be highly beneficial.

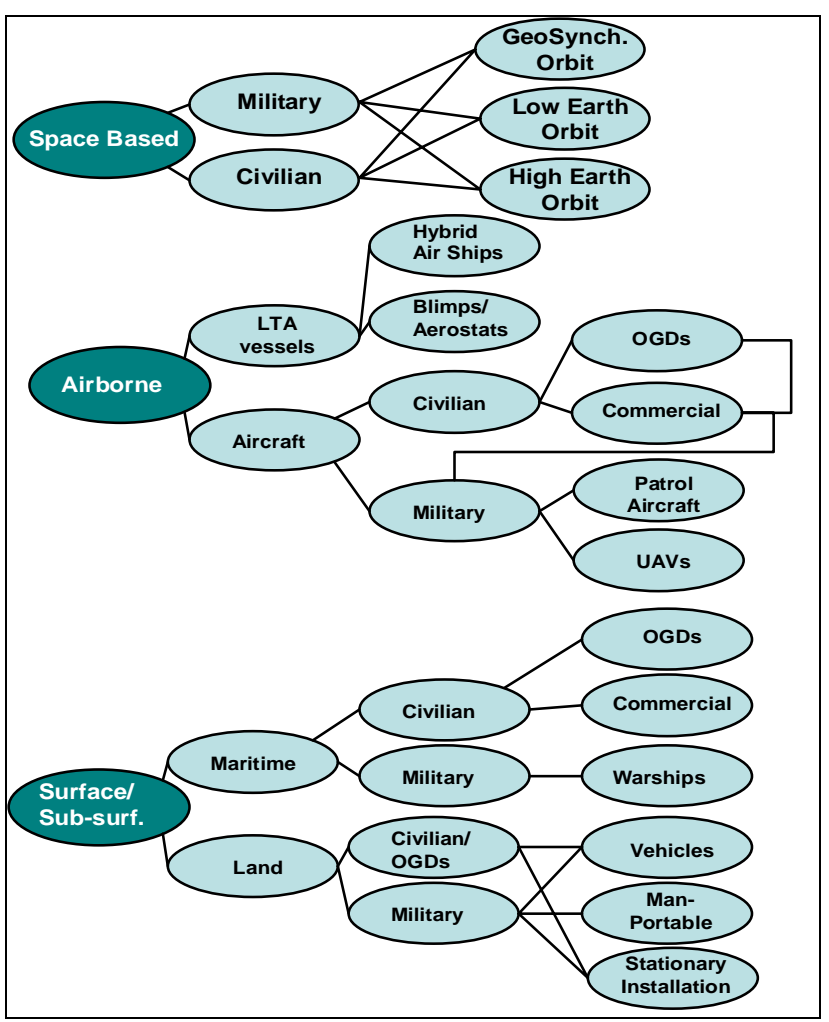

Figure 2: Platform Sources.

\subsection{Adaptation of the processing}

As additional sources of ISR and communication bandwidth become available, the optimum choice of processing will change. The nature of the products required by the end-users will also evolve. The A-C4ISR architecture must support an evolving processing environment. One of the greatest constraints governing the ability to do ADA is the lack of communication channels and bandwidth constraints, since most options ultimately 
require the use of a satellite communications link. Table 1 gives [3] some indication of the challenges in this area. Regardless of the option chosen, satellite time costs about \$1-2 per minute, which is a significant expense if multiple channels are required on a continuous basis.

Table 1 : Typical communications links for the Arctic.

\begin{tabular}{|l|l|l|l|}
\hline Link Type & \multicolumn{1}{|c|}{ Provider } & Coverage & \multicolumn{1}{c|}{ Bandwidth/ } \\
\hline $\begin{array}{l}\text { Satellite - } \\
\text { Polar Orbit }\end{array}$ & Iridium & Global & $2.4 \mathrm{Kbps} /$ channel \\
\hline $\begin{array}{l}\text { Satellite- } \\
\text { Geosynch. } \\
\text { Orbit }\end{array}$ & Inmarsat-B & $\begin{array}{l}<60-75^{\circ} \mathrm{N} \\
\text { Longitude } \\
\text { dependent }\end{array}$ & $\begin{array}{l}<128 \mathrm{Kbps} / \\
\text { channel }\end{array}$ \\
\hline $\begin{array}{l}\text { Satellite- } \\
\text { Geosynch } \\
\text { Ku-band }\end{array}$ & $\begin{array}{l}\text { Telesat Canada } \\
\text { (TSC) }\end{array}$ & $<80^{\circ} \mathrm{N}$ & $<4 \mathrm{Mbps} /$ channel \\
\hline $\begin{array}{l}\text { Satellite- } \\
\text { Geosynch } \\
\text { Ka-band }\end{array}$ & Telesat Canada & $<80^{\circ} \mathrm{N}$ & $\begin{array}{l}<500 \\
\mathrm{kbps} / \mathrm{channel}\end{array}$ \\
\hline $\begin{array}{l}\text { Microwave } \\
\text { Link+ } \\
\text { Geosynch } \\
\text { Satellite }\end{array}$ & $\begin{array}{l}\text { TSC/Raytheon- } \\
\text { High Altitude } \\
\text { Data Com. Sys. }\end{array}$ & $\begin{array}{l}\text { CFS Alert } \\
\text { to Eureka }\end{array}$ & 6.312 Mbps [4] \\
\hline $\begin{array}{l}\text { Satellite- } \\
\text { Polar Orbit }\end{array}$ & $\begin{array}{l}\text { NOAA- } \\
\text { Argos Data } \\
\text { Collection System }\end{array}$ & Global & $\begin{array}{l}\text { Short Message } \\
\text { Service only }\end{array}$ \\
\hline
\end{tabular}

However, in time, the number of satellite communications options may improve with new sources coming on line. For example, one option that has been/is being considered for the future is a small network of polar orbiting satellites in Molnya (highly eccentric) orbits that might provide more dedicated channels.

Table 2 shows some of the additional challenges involved with providing ADA when considering the bandwidth requirements for various types of data associated with sensors or reporting formats.

Table 2: Typical data rate requirements data and video [4].

\begin{tabular}{|l|l|}
\hline Data Type & Bandwidth Requirements \\
\hline AIS & 24 bps (average) \\
\hline IFF/SSR & $9.33 \mathrm{bps} /$ aircraft \\
\hline OTH-Gold & $182 \mathrm{bps} /$ contact (av.) \\
\hline Standard TV quality video & $4 \mathrm{Mbps}$ \\
\hline DVD video & $9.8 \mathrm{Mbps}$ \\
\hline MPEG-2 & $15 \mathrm{Mbps}$ (NATO Stanag 4609) \\
\hline MPEG-2/ & $1.5 \mathrm{Mbps}$ \\
MPEG-1(low definition) & \\
\hline
\end{tabular}

A predator type Uninhabited Aerial Vehicle (UAV) with an Electro-Optical/Infrared (EO/IR) payload would probably require a bandwidth of at least $2 \mathrm{Mbps}$ for streaming video, and an additional 10-15 Mbps for SAR imagery. At lower latitudes this may not be such a challenge, but in the Arctic environment this would place a considerable strain on communications bandwidth.

Given that streaming video constitutes such a obvious difficulty, it may be more prudent to restrict ourselves to individual images and short video clips depending on the situation and bandwidth saturation. The bandwidth problem also constitutes a challenge with respect to sensor integration and computational requirements. Because of low bandwidth, more processing may be required locally at the Arctic sensor sites before transmitting the reduced information set south. This introduces an additional consideration in that greater processing requirements generally require higher power requirements, which in turn puts a greater strain on the semi-autonomous requirements of the remote Arctic sensors.

Table 3 provides some indication of complex nature of the sensor mix required for Arctic ISR in order to provide detection, tracking, classification and identification.

Some of the sensors listed above have varying degrees of complexity; for example the radar can be as simple as a narrow band non coherent maritime surveillance radar only capable of providing detections and tracks, or as complex as a wide-band multi-function (phased) array capable of SAR/ISAR and High Resolution Range signature classification/identification. The bandwidth requirements would vary accordingly.

Depending on the architecture and the communications protocol employed, there will also be issues of queuing delays (data, images etc.) caused by bandwidth saturation that must be considered. Figure 3 implies some of the problems that may be incurred by bandwidth saturation. Figure 4 is used to give a general impression of the bandwidth requirements for various applications.

\subsection{Exploitation of data by diverse end- users}

The organizations that contribute to the building of the ADA will expect to be able to use the results. The requirements for how this information will be used are very diverse. It can include users who want access to unprocessed data in order to feed it into their own systems for processing. These systems may take the form of a legacy system.

Other users that don't have this level of capability may expect the information to be provided as a web service. These services can include a web based Geographic Information System (GIS) display such as Google Earth as well as other web based analysis tools.

\subsection{Different display capabilities for diverse end-users}

Since the organizations that contribute to the building of the ADA will require different products, it is expected that they will also have different display requirements. Coast Guard and the Military may need to display individual tracks and the relevant information associated with these tracks. Other users such as national and international 
Table3: Generic Sensor Mix for Arctic Surveillance Requirements. Red shading indicates a definite crypto (security) requirement.

\begin{tabular}{|l|c|c|c|c|}
\hline Platforms & $\begin{array}{l}\text { EO/IR/ } \\
\text { Visual/ } \\
\text { Multi- } \\
\text { Spectral/ } \\
\text { Hyper- } \\
\text { Spectral }\end{array}$ & Radar & $\begin{array}{c}\text { AIS/ } \\
\text { IFF/ } \\
\text { SSR/ } \\
\text { ADS-B }\end{array}$ & $\begin{array}{c}\text { ELINT/ } \\
\text { SIGINT }\end{array}$ \\
\hline $\begin{array}{l}\text { Civ.Aircraft- } \\
\text { fixed/rotary } \\
\text { wing }\end{array}$ & Yes & Yes & Yes & No \\
\hline $\begin{array}{l}\text { Mil. Aircraft- } \\
\text { fixed/rotary } \\
\text { wing and UAV }\end{array}$ & Yes & Yes & Yes & Yes \\
\hline $\begin{array}{l}\text { Civilian } \\
\text { Shipping }\end{array}$ & Yes & Yes & Yes & No \\
\hline Military Vessels & Yes & Yes & Yes & Yes \\
\hline $\begin{array}{l}\text { Blimps/ } \\
\text { Aerostats }\end{array}$ & Yes & Yes & Yes & Yes \\
\hline $\begin{array}{l}\text { Land Based } \\
\text { Stationary } \\
\text { Civilian }\end{array}$ & Yes & Yes & Yes & Yes \\
\hline $\begin{array}{l}\text { Land Based } \\
\text { Stationary } \\
\text { Military }\end{array}$ & Yes & Yes & Yes & Yes \\
\hline $\begin{array}{l}\text { Land Based } \\
\text { Vehicle } \\
\text { (military) }\end{array}$ & Yes & Yes & Yes & Yes \\
\hline $\begin{array}{l}\text { Satellite- } \\
\text { Civilian } \\
\text { Commercial }\end{array}$ & Yes & Yes & Yes(?) & No \\
\hline $\begin{array}{l}\text { Satellite- } \\
\text { Military }\end{array}$ & & Yes & & Yes \\
\hline Man Portable & Yes & \\
\hline $\begin{array}{l}\text { AIS: Automatic Identification System (Civilian) } \\
\text { ADS-B:Automatic Dependent Surveillanc-Broadcast } \\
\text { IFF: Identification Friend or Foe System (Military) } \\
\text { SSR: Secondary Surveillance Radar (Civilian IFF) }\end{array}$ \\
UWS: Under Water Sensors (Mil. electric, magnetic., acoustic) \\
\hline
\end{tabular}

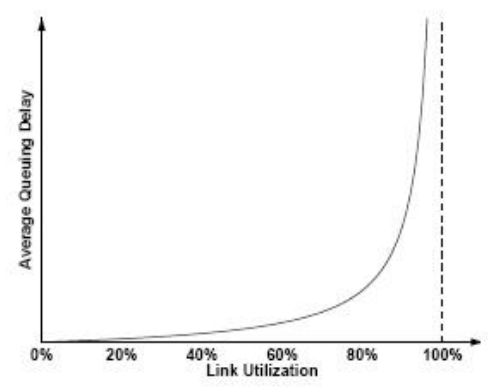

Figure 3: Queuing Delay versus System Utilization $\alpha /(1-\alpha)$ where $\alpha$ is the link utilization.[4]

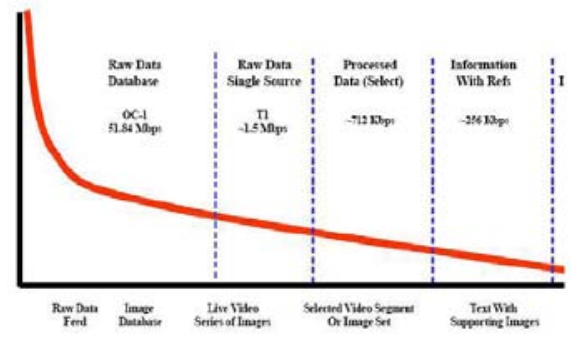

Figure 4: "Bandwidth Required to Support Transfer of the Continuum From Data to Information"[4]

fishing organizations may need only view the level of activity in different regions.

The end-users in different organizations will have legacy interfaces. Any new interface(s) will require additional training. It is desirable to avoid the cost associated with these changes.

\section{Service-Oriented Architecture}

The current C4ISR capabilities in use today within the Canadian government, the Department of National Defence (DND), and the Department of Defense (DoD) in the United States (US) are primarily client-server in nature (although that is changing). The obvious approach would be to apply that C4ISR solution approach to the Arctic requirement as discussed in this paper but it is problematic. Section 2 of this paper clearly highlights some of the challenges associated with carrying out C4ISR in the Canadian Arctic.

Client-server based C4ISR systems are monolithic in nature and usually result in stove-piped solutions that are not easily reconfigured, rigid in structure, and usually push data to its consumers rather than allowing for an intelligent pull and maximum exploitation of the data and information available in these systems. Furthermore, the Arctic environment poses many constraints on a C4ISR solution, which are not necessarily new to these systems. The remoteness and harshness of the Arctic environment when coupled with limited bandwidth constraints and a clear lack of manpower to man and run these systems suggest that a different approach is required. The enduser of such systems must be able to: 1) remotely reconfigure these systems, 2) access, pull, and explore the information and data available in these systems intelligently to support fluid operations, and 3) allow for the easy integration of new sensors and information sources as well as, new functionality and capabilities as they become available. Current directions in the US DoD and within the DND support the use of a service oriented architecture to address the Canadian Arctic C4ISR requirements discussed in this paper.

Current legacy C4ISR systems are generally built as client-server systems. An example of such a system is the Global Command and Control System - Maritime (GCCS-M), which is evolving and transitioning towards a service oriented architecture [3]. The focus of this 
transformational strategy is focused on enhancing platform networked capabilities while achieving a high level of system interoperability. These types of systems are generally characterized by:

- Network dissemination and point-to-point exchange of data, consistent business logic, developing standard community syntax and semantics, developing compatible platforms, a development community focused on code reuse, using multiple vendor solutions, and using both heavy and thin clients.

- Network connections that have: little or no visibility or access to services; different directories, security, and access processes; different data representations; numerous uncoordinated transformations; and data filtered by local systems.

The transformation strategy for such systems has centred on work-nets, capabilities, and relationships that include: network visualization and dissemination of data and information as services; continuing to develop standard community syntax and semantics; developing compatible platforms and technologies; adopting publish and subscribe services, peer-to-peer computing, web services, application and intelligent thin clients with a focus on fused data (i.e., on information rather than just data).

This evolution and transition is clearly towards a service oriented architecture that focuses on developing visible and accessible data and services that have: common network services, common representations, common catalogues and directories, re-usable service components, supporting publish and subscribe services for data and information exchange, and developing systems that are loosely-coupled, composable, and easy to upgrade/update and deploy.

The advantage of continuing with a client-server architecture is that it is well understood and requires little investment to support ADA; however, this approach will have problems addressing the A-C4ISR issues discussed above.

\subsection{SOA Overview}

The exact definition of what constitutes a SOA is open for debate; however, it is generally acknowledged that a Service Oriented Architecture (SOA) is the result of careful and consistent deployment of services. The US Defense Information Systems Agency (DISA) defines a SOA to be a set of principles that together define an architecture that is loosely coupled and comprised of service providers and service consumers that interact according to a negotiated contract or interface. A SOA is an architectural approach that emphasizes the delivery of functionality and new capabilities as services, whether or not these services are based upon legacy systems or through the creation of new capabilities as services to meet system design requirements [5-6]. Furthermore, a SOA is not just an architecture of services seen from a technology perspective, but the policies, practices, and frameworks by which it is ensured that the right services are provided and consumed [7]. An important aspect of a service-oriented architecture is that it separates the service's implementation from its interface. More importantly, a service-oriented architecture has a number of characteristics associated with its services that reflects the different principles and set of tradeoffs used by the designers. In particular, services must be discoverable and dynamically bound, self-contained and modular, interoperable, be loosely coupled, have a networkaddressable interface, have coarse-grained interfaces, be location-transparent, and composable [8-9].

A key strength of a SOA is in its ability to address a broad range of integration issues and problems well beyond that normally associated with the integration of sensors, information, and data sources. It allows for the integration of groups and communities of interest having user specific requirements through the implementation of services that provide both caveat filtering and distributed picture management (e.g., multi-agency coordination). It also allows services to be utilized in ways that were never envisioned as part of the initial design requirements to accommodate emergent behaviors. More importantly, a SOA integration approach supports the development of a migration strategy that will allow a stakeholder to integrate his current sources, functionality, and capabilities associated with his legacy systems as services in a SOA while planning for the replacement, enhancement, and expansion to meet his future operational requirements that match available resources.

\subsection{SOA Test-bed}

Ongoing research at Defence R\&D Canada (DRDC) has resulted in a sensor integration test-bed based on the framework shown in Fig. 5. The framework will provide the following services to components that are plugged into the framework: Discovery, Directory and Lookup, Filtering, Status Monitoring, Logging, Alert and Notification, and Workflow composition and management.

The test-bed is implementing a multi-source ad-hoc distributed C4I system that will demonstrate improved track management and fusion operations and improved generation and distribution of a common operating picture.

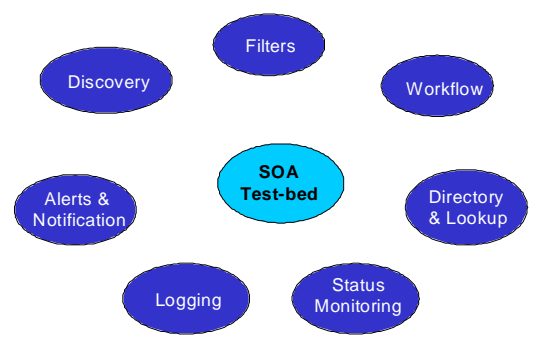

Figure 5: SOA Test-bed Framework services. 
The services shown in Figure 5 are the SOA Test-bed's framework services shown in Figure 8 and are defined as follows:

Discovery - The discovery service allows potential users of a service to look up its features and details of its use described in Web Service Description Language (WSDL).

Directory/Look-up - While the discovery service will provide the identity and other invariant details about a service, the directory or look-up service will provide more concrete items, such as hardware or network addresses, given the identity of the service.

Filtering - A filter server provides a place to register and look-up previously defined data filters. These filters will be used to create input and output services for managing the caveated data and information. It could also be used as a repository for policy based filters and/or multisecurity/multi-jurisdictional filters for use by other plug-in components.

Status Monitoring - The test-bed will provide a consolidated view of various events in the current domain, including framework status, plug-in component state, measured timing data, errors, warnings, alerts, etc.

Logging - The test-bed will provide a log of messages for domain-wide display and storage.

Alerts and Notification - The test-bed will provide a service to publish and/or email alerts and notifications.

Workflow Composition - Workflow composition is required to support service integration. This consists of an application to launch plug-in services and to browse the registry service to find appropriate plug-ins.

The types and roles of services that this test-bed supports are illustrated in Fig. 6, and described below.

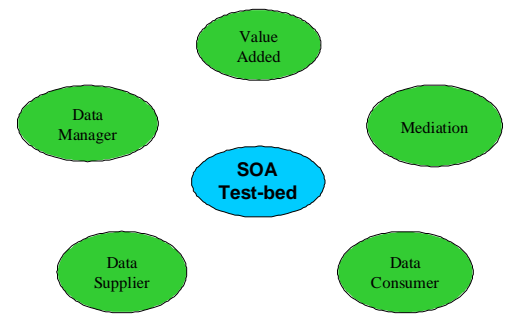

Figure 6: SOA Test-bed Component/ Plug-in types

The components and plug-in types shown in Figure 6 include such things as the sensor inputs, adaptors, and charts shown in Figure 8, and are defined as follows:

Data Manager Role - The test-bed supports a network of providers of reports, tracks, or entities. A data provider that has the ability to retrieve or modify the data takes on the roles and responsibilities of a data manager. Data managers, in addition to the standard manager operations (create, update, delete, query, and notify) may be required to merge and manage the names of track objects.

Value-Added Component Role - The test-bed will support for components that automate command centre tasks such as data fusion and alert generation. These components will generally be consumers of managed data, and in turn will be users of services on other information managers to produce new information objects or modify existing ones.

Mediation Role - The test-bed will provide components that mediate the exchange of information between registered services.

Data Consumer Role - The test-bed will support pure consumer components. User displays are examples of these. Consumers will look for suppliers but will not publish any objects. Certain tactical decision aids may fall into this category, such as operator alerts.

Data Supplier Role - The test-bed will support pure data suppliers. Most of the information that is entered into the framework will be managed, so therefore will fall into the category of data managers. Information that is not managed such as chat traffic falls into the data supplier category.

\section{Proposed Architecture}

Here we propose the following architecture to support Arctic C4ISR.

\subsection{Test Architecture}

Figure 7 provides a simplified version of the test-bed architecture. The test-bed is a work in progress but the research to date provides sufficient insight into the potential of the SOA approach to allow us to make the case for its use in support of Arctic C4ISR.

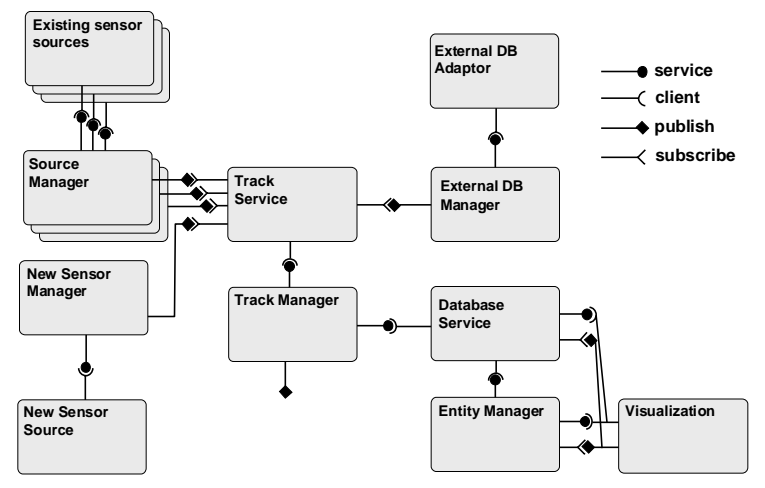

Fig

ure 7: SOA Test-bed Simplified Architecture.

Figure 7 shows the high level view of the relevant components and the relationship between them. These components are described below. 
Source Manager - Supports pure data suppliers of track information. It has the ability to:

- retrieve or modify the data by taking on the roles and responsibilities of a data manager for this source;

- supply a Globally Unique IDentifier (GUID) for each object;

- process all requests for creation, deletion, and modification of objects funnel through the manager so that conflicting operations do not occur;

- provide reach back for reports delivered from the sensor system;

- be responsible for publishing any changes or notification of changes to the database as they occur;

- be responsible for publishing any changes or notification of changes; and

- describe and provide their services.

Track Manager- will support a network of providers of reports, tracks, or entities. It will:

- be responsible for the persistence and lifecycle maintenance of each object allocated to it;

- funnel all requests for creation, deletion, and modification of objects through it so that conflicting operations do not occur;

- perform standard manager operations of create, update, delete, query, and notify;

- (may) be required to merge and manage the names of track objects; and

- be responsible for publishing any changes or notification of changes to the database as they occur.

Track Service - This component provides the services that automate command centre tasks such as data correlation, data fusion and alert generation. These components will generally be consumers of managed data, and in turn will be users of services on other information managers to produce new information objects or modify existing ones.

External Database Manager - Provides access to external databases such as Lloyds and Jane's that provide non-track information that may be used by the track services. This component provides capabilities similar to the source manager, usually as links to relevant information.

Entity Manager - An entity is an uniquely identified object (a unit, a piece of equipment, a person, a facility, a manmade feature, a natural feature) that exists. Entities can be any significant object that the end-user must deal with, such as platforms or friendly assets. The test-bed entity manager will support pure consumer components such as the visualization component shown in Fig. 7. Consumers will look for suppliers but will not publish any objects.

\subsection{Arctic SOA}

Figure 8 illustrates a possible mapping of the elements and roles of the A-C4ISR onto the test-bed architecture.
Providers - On the left of the diagram we have examples of pure data suppliers. This can include a variety of

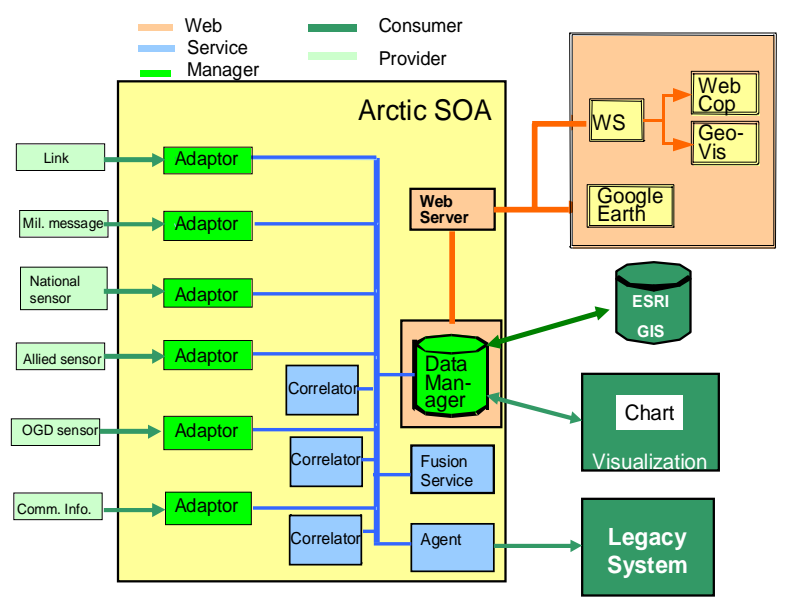

Figure 8: Simplified SOA Test-bed Architecture.

providers that can range from Defence sources to commercial information from the web.

Managers - Most of the information that is entered into the framework will be managed. This capability is provided by data managers that provide a number of functions including adapting the information to eXtensible Markup Language (XML) format for use by the system.

Service - A SOA provides a number of services of which only a few examples are shown here. Shown here are a number of correlators to support the different track types and a service to support track-to-track fusion.

Consumer - On the right are shown some sample data consumers. This can include a GIS such as the one provided by ESRI. It can also include a variety of visualization tools (e.g., charts). It is also possible to provide a one-way feed to a classified or unclassified legacy system.

Web - Data can also be consumed using web based applications that make use of web services provided by the architecture. An example of this is the display of track data in Google Earth. An example from the SOA test-bed is illustrated in Fig. 9.

Diverse information sources - One of the objectives is to leverage on all available sources. These sources will need to control access to their data. Although not explicitly illustrated here, this capability can be achieved with the use of caveat filters. Furthermore, the availability of this data must support the concept of the data and information being pervasive in nature. That is, it must not only be available to anyone who requires it but the right data/information must get to the right people in the right time frame if it is to be effectively leveraged by the user community to support ADA. 


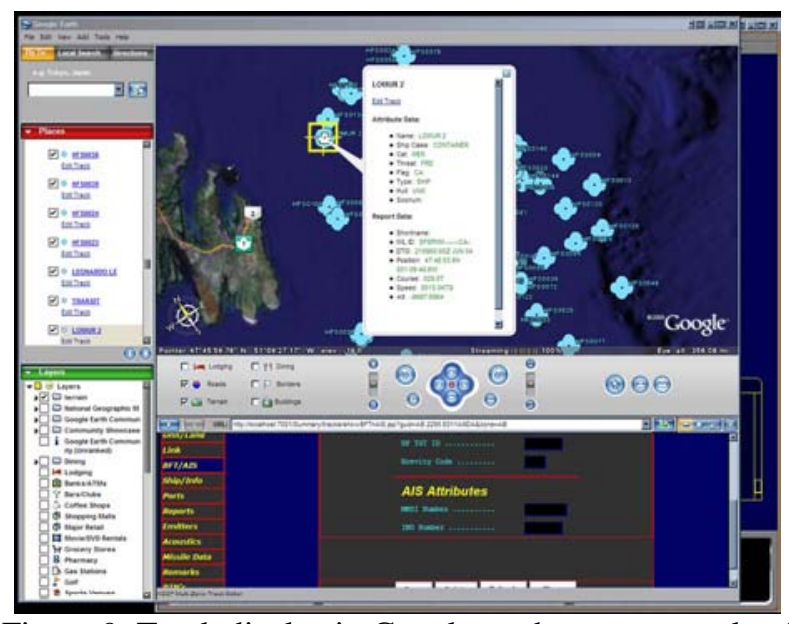

Figure 9: Track display in Google earth as an example of a web-based service.

\subsection{How SOA address Arctic C4ISR issues}

Continual change to the ISR mix - The C4ISR architecture must be capable of accommodating new information and surveillance sources as they become available. Figure 7 illustrates the addition of a new sensor source. This can be supported with a source manager and possibly a new correlator.

Adaptation of the processing - The A-C4ISR architecture must support an evolving processing environment. This can be achieved through the addition of additional services such as correlators and fusion capabilities, as well as recognizing that the SOA is both operating system and language agnostic.

Exploitation of data by diverse end-users - We have illustrated with the use of our existing test-bed the capability to exploit the information in a variety ways. The end-user can subscribe to the combination of services required to support their activity within the SOA. They may also host the required functionality outside the SOA as a web service or in a legacy system as illustrated in Fig.8.

Different display capabilities for diverse end-users We have illustrated with the use of our existing test-bed the capability to exploit the information in a variety ways. This includes the use of web-based tools as illustrated with Google Earth, the use of GIS systems such as ESRI or in a military context.

\section{Conclusion}

In this paper, we have presented the challenges that will be faced in maintaining Arctic Domain Awareness and the A-C4ISR issues that will result from these challenges. We have discussed the characteristics of the legacy clientserver system and how it limits the exploitation of all available data. The characteristics of a SOA that could address some of these issues are presented. Based on upon our SOA research and our experience in developing a testbed to support sensor integration we have proposed an architecture that can contribute to addressing these AC4ISR issues. This includes: 1) accommodating diverse information sources with the use of caveat filters, 2) continual change to the ISR mix with source managers and track services, 3) adaptation of the processing through the addition of new services, 4) exploitation of data by diverse end-users by subscribing to the combination of services or through a web service, and 5) different display capabilities for diverse end-users through the use of webbased tools or the use of GIS systems. Our experience and results to date strongly suggest that the benefits derived by adapting a SOA warrant the effort needed to fully develop this capability.

\section{References}

[1] Mr. J. P. High, Dir. of the USCG's MDA Program Integration Office, Test. before the Subcommittee on C.G. \& Maritime Transportation Committee on Transport. and Infrastr., U.S. House of Representatives, 6 October 2004. http://www.house.gov/transportation/cgmt/10-06-04/1006-04memo.html

[2] John VanOsdol, Auxiliary White Paper On Maritime Domain Awareness: Revision 2, National Director, Maritime Domain Awareness, US Coast Guard Auxiliary, February , 2005 http://www.americaswaterwaywatch.org/ PDF/MDAwhitepaperv2.0-Feb.\%202005.pdf

[3] Web Site, Web Pages of Jerry Proc-CFS Alert, , accessed Feb. 1, 2007, http://jproc.ca/rrp/alert.html

[4] MacLeod, Mathew R.: "Northern Watch TDP Communications Study (DRAFT)", Defence R\&D Canada - CORA, Technical Memorandum, DRDC CORA TM 2007-009, May 2007, 67 pages,

[5] Web site, "Network Centric Operations Industry Constortium (NCOIC)." http://www.ncoic.org/home

[6] Cape Clear Software Inc, "Principles of SOA Design," A Whitepaper from Cape Clear Software Inc, 2004. http://www.capeclear.com,

[7] Sprott, David and Wilkes, Lawrence: "Understanding Service-Oriented Architecture," Microsoft Architect Journal, CBDI Forum, January 2004. http://msdn2.microsoft.com/en-us/library/aa480021.aspx,

[8] Web site, "Netcentric Enterprise Solutions for Interoperability

(NESI).’http://nesipublic.spawar.navy.mil/,

[9] Web site, "Network Centric Operations Industry Constortium (NCOIC).” http://www.ncoic.org/home, 